\title{
Statement on the retraction of "Officer characteristics and racial disparities in fatal officer-involved shootings"
}

\author{
Joseph Cesario $^{1}$ and David J. Johnson ${ }^{1,2}$ \\ ${ }^{1}$ Michigan State University \\ ${ }^{2}$ University of Maryland at College Park
}

July 8,2020

We recently requested PNAS retract our article, "Officer characteristics and racial disparities in fatal officer-involved shootings" (Johnson et al., 2019). This statement serves as explanation for this decision.

\section{The Short Answer}

We were careless when describing the inferences that could be made from our data. This led to the misuse of our article to support the position that the probability of being shot by police did not differ between Black and White Americans. To be clear, our work does not speak to this issue and should not be used to support such statements. We accordingly issued a correction to rectify this statement (Johnson \& Cesario, 2020).

Although our data and statistical approach were valid to estimate the question we actually tested (the race of civilians fatally shot by police), given continued misuse of the article we felt the right decision was to retract the article rather than publish further corrections. We take full responsibility for not being careful enough with the inferences made in our original article, as this directly led to the misunderstanding of our research.

This was the sole reason for our decision to retract the article; this decision had nothing to do with political considerations, "mob" pressure, threats to the authors, or distaste for the political views of people citing the work approvingly.

\section{The Long Answer}

Our article reported two main results: First, we provided information about the officers involved in fatal police shootings. This officer information had never been comprehensively collected and provided the first insight into the police who have shot civilians. Second, we found there was no relationship between the race of officers and the civilians they fatally shot when controlling for county racial demographics and crime rates.

While the data and statistical approach we took to answer these questions was appropriate, the mistake we made was drawing inferences about the broader population of civilians who interact with police rather than restricting our conclusions to the population of civilians who were fatally shot by the police. We are thankful to Knox and Mummolo (2020) for highlighting this error.

To better understand our thinking while writing the article, it may be helpful to place this work in the broader context of research on fatal police shootings.

\section{Broader Context}

The starting point for understanding the approach of Johnson et al. 2019) is the main criticism that has arisen of it, that we did not calculate the probability that a person is shot given their race, i.e., $\mathrm{P}$ (shot|race).

As we should have made more clear in the introduction to our article, the reason we did not calculate $\mathrm{P}$ (shot|race) is that many researchers have already calculated approximations to this quantity. Indeed, benchmarking approaches (in which the number of Black and White civilians shot is compared to the proportion of Black and White civilians of some relevant pool) have been widely used for decades.

Benchmarking calculations and their derivations generally point to the same conclusion: Relative to the proportion of Black civilians in the U.S., Black Americans are shot more than we would expect. However, relative to various proxies for the proportion of Black civilians who commit violent crime, Black Americans are not shot more than we would expect. This has been consistently shown for the majority of fatal shootings (90-95\%) where the citizen shot is an immediate threat to an officer or other citizen 
(Cesario et al., 2019; Fyfe, 1980; Goff et al., 2016; Inn et al., 1977; Tregle et al., 2019; Worrall et al., 2020), though some evidence has been presented that racial bias may be present in the remaining types of shootings (Ross et al., in press). The lack of racial disparity once violent crime rates are taken into account has also been shown in papers using more complex analytic approaches than proportion comparisons (Fryer, 2016; Mentch, 2020; Ross et al., in press).

One problem with such benchmarking approaches is that debate arises about whether it is more informative to compare the number of civilians shot to overall population proportions or to proxies for violent crime proportions. Indeed, one will obtain different results depending on what one thinks is the relevant comparison group: calculating $\mathrm{P}$ (shot|race) for the entire population will likely show evidence of anti-Black disparity, whereas calculating $\mathrm{P}$ (shot|race) for the pool of civilians who have violent interactions with the police will likely show no evidence of antiBlack disparity.

It is in this context that Johnson et al. (2019) was produced. Rather than debating which pool of civilians is the correct comparison group, we tested a less broad question that could be answered with current data: Is there a relationship between the race of officers and the civilians they fatally shot? However, this does not address the larger question of how race impacts the probability of being shot by police.

\section{Future Directions}

Readers might wonder why we chose to examine only police encounters that resulted in fatal shootings of civilians versus encounters that did not, as the latter is necessary to estimate racial disparities in the probability of being shot. The reason is that current analyses on police use of force are limited by the lack of comprehensive and complete national databases on police interactions with the public, where force is used and where force is not used.

Without more data on police-civilian encounters, it is difficult to estimate racial bias in police use of force. This lack of data is why we collected information about all officers who fatally shot civilians in 2015, an undertaking that took more than 1800 hours over three years. The lack of detailed, publiclyavailable information on police-civilian encounters is unacceptable and necessary for a more complete understanding of where bias exists in police-civilian interactions.

\section{References}

Cesario, J., Johnson, D. J., \& Terrill, W. (2019). Is there evidence of racial disparity in police use of deadly force? Analyses of officer-involved fatal shootings in 2015-2016. Social Psychological Personality Science, 10, 586-595.

Fryer, R. G. (2016). An empirical analysis of racial differences in police use of force (tech. rep.). National Bureau of Economic Research.

Fyfe, J. J. (1980). Geographic correlates of police shooting: A microanalysis. Journal of Research in Crime and Delinquency, 17(1), 101-113.

Goff, P. A., Lloyd, T., Geller, A., Raphael, S., \& Glaser, J. (2016). The science of justice: Race, arrests, and police use of force. Center for Policing Equity.

Inn, A., Wheeler, A. C., \& Sparling, C. L. (1977). The effects of suspect race and situation hazard on police officer shooting behavior. Journal of Applied Social Psychology, 7(1), 27-37.

Johnson, D. J., \& Cesario, J. (2020). Correction for Johnson et al., Officer characteristics and racial disparities in fatal officerinvolved shootings. Proceedings of the $\mathrm{Na}$ tional Academy of Sciences, 117(16), 91279127.

Johnson, D. J., Tress, T., Burkel, N., Taylor, C., \& Cesario, J. (2019). Officer characteristics and racial disparities in fatal officerinvolved shootings. Proceedings of the $\mathrm{Na}$ tional Academy of Sciences, 116(32), 1587715882.

Knox, D., \& Mummolo, J. (2020). Making inferences about racial disparities in police violence. Proceedings of the National Academy of Sciences, 117(3), 1261-1262.

Mentch, L. (2020). On racial disparities in recent fatal police shootings. Statistics and Public Policy, 7(1), 9-18.

Ross, C. T., Winterhalder, B., \& McElreath, R. (in press). Racial disparities in police use of deadly force against unarmed individuals persist after appropriately benchmarking shooting data on violent crime rates. Social Psychological and Personality Science.

Tregle, B., Nix, J., \& Alpert, G. P. (2019). Disparity does not mean bias: Making sense of observed racial disparities in fatal officer-involved shootings with multiple benchmarks. Journal of Crime and Justice, 42(1), 18-31.

Worrall, J. L., Bishopp, S. A., \& Terrill, W. (2020). The effect of suspect race on police offi- 
cers' decisions to draw their weapons. Justice

Quarterly, 1-20. 